EXPERIMENTAL STUDY

\title{
Analysis of the interaction between human steroid 21-hydroxylase and various monoclonal antibodies using comparative structural modelling
}

Ricardo Núñez Miguel $^{1,2}$, Shu Chen ${ }^{1}$, Laleh Nikfarjam ${ }^{3}$, Shiro Kominami ${ }^{3}$, Byron Carpenter ${ }^{1}$, Chiara Dal Pra ${ }^{1,4,5}$, Corrado Betterle ${ }^{5}$, Renato Zanchetta ${ }^{5}$, Takashi Nakamatsu ${ }^{1,4}$, Michael Powell ${ }^{1}$, Rachel Hewer ${ }^{1}$, Tom L Blundell ${ }^{2}$, Bernard Rees Smith ${ }^{1,4}$ and Jadwiga Furmaniak ${ }^{1,4}$

${ }^{1}$ FIRS Laboratories, RSR Ltd, Parc Ty Glas, Llanishen, Cardiff CF14 5DU, UK, ${ }^{2}$ Department of Biochemistry, University of Cambridge, 80 Tennis Court Road, Cambridge CB2 1GA, UK, ${ }^{3}$ Faculty of Integrated Arts and Sciences, Hiroshima University, Higashihiroshima, $739-8521$ Japan, ${ }^{4}$ Department of Medicine, Cardiff University, Heath Park, Cardiff CF14 4XN, UK and ${ }^{5}$ Department of Medical and Surgical Sciences, University of Padova, Via Ospedale Civile 105, 35128 Padova, Italy

(Correspondence should be addressed to J Furmaniak at FIRS Laboratories address; Email: firs@rsrltd.eclipse.co.uk)

\begin{abstract}
Objective: To study the interaction between human steroid 21-hydroxylase (21-OH) and monoclonal antibodies (MAbs) to 21-OH directed to 3 different epitopes recognised by 21-OH autoantibodies characteristic of autoimmune Addison's disease.

Design: Build comparative structural models of 21-OH, 21-OH MAbs and complexes of 21-OH-21-OH MAbs and study the effects of 21-OH MAbs on 21-OH enzyme activity. Then, analyse the relationship between sites important for binding of 21-OH MAbs and 21-OH autoantibodies and sites important for 21-OH enzyme activity.

Methods: Variable (V) regions of 21-OH MAbs (M21-OH1, M21-OH3, M21-OH5) were sequenced and models of the MAbs built using structures of antibodies in the database as templates. A comparative model of 21-OH was built using the crystal structure of rabbit cytochrome p450 2c5/3LVdH as template. 21-OH enzyme activity was measured in terms of conversion of $\left[{ }^{3} \mathrm{H}\right]$ progesterone to deoxycorticosterone and the effect of purified MAb IgGs on 21-OH enzyme activity was assessed.

Results: M21-OH1, M21-OH3 and control MAb had no effect on 21-OH enzyme activity with $88.8 \% \pm 24 \%(n=6), 86.7 \% \pm 7.6 \%(n=6)$ and $86.5 \% \pm 10.6 \%(n=6)$ of activity remaining in the presence of the respective IgGs. This was consistent with the epitopes for M21-OH1 and M21-OH3 being located distant from 21-OH enzyme active sites in our 21-OH model. The epitope for M21-OH5 which inhibited $21-\mathrm{OH}$ enzyme activity $(48.5 \pm 8.3 \%$ activity remaining; $P<0.001$ compared with control MAb IgG) was found close to the redox protein binding site in our 21-OH model.

Conclusions: A comparative model of 21-OH has been produced. Analysis of experimental data in the context of the model suggests that M21-OH5 inhibits 21-OH enzyme activity through interference with redox protein binding.
\end{abstract}

European Journal of Endocrinology 153 949-961

\section{Introduction}

Autoantibodies to steroid 21-hydroxylase (21-OH) are characteristic of autoimmune Addison's disease (1). 21-OH autoantibodies react with conformational epitopes located predominantly in the central and the Cterminal parts of 21-OH (amino acids (aa) 280-495) and have the ability to inhibit 21-OH enzyme activity in vitro $(2-5)$. Some of the mouse monoclonal antibodies (MAbs) to 21-OH inhibit binding of 21-OH autoantibodies to $21-\mathrm{OH}$ and the epitopes recognised by these MAbs involve three 21-OH aa regions: aa 391405 (epitope region (ER) 1), aa 406-411 (ER2) and aa 335-339 (ER3) (6). Previous studies have indicated that ER2 and ER3 are parts of two distinct major epitopes recognised by 21-OH autoantibodies while ER1 is part of a minor epitope (6).
In order to gain a better insight into the interaction between 21-OH MAbs and 21-OH, we have constructed structural models of 21-OH, 21-OH MAbs and the MAbs in complex with 21-OH. The effect of 21-OH MAbs on 21-OH enzyme activity has also been studied. The relationship between the sites on the 21-OH molecule recognised by 21-OH MAbs and the sites recognised by 21-OH autoantibodies was then analysed.

\section{Materials and methods}

\section{1-OH MAb preparation and characterisation}

21-OH MAbs (M21-OH1, -3 and -5) were obtained as described previously (6) from BALB/C mice immunised with highly purified recombinant human 21-OH-GST fusion proteins. IgGs were isolated from the culture 
supernatants using chromatography on ProsepA (Millipore UK Ltd, Watford, Herts, UK) according to the manufacturer's instructions, dialysed against phosphate

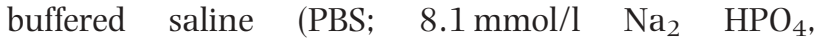
$1.5 \mathrm{mmol} / \mathrm{l} \quad \mathrm{KH}_{2} \mathrm{PO}_{4}, \quad 2.7 \mathrm{mmol} / \mathrm{l} \mathrm{KCl}, \quad 137 \mathrm{mmol} / \mathrm{l}$ $\mathrm{NaCl}, \mathrm{pH} 7.3)$ and stored in aliquots at $-70{ }^{\circ} \mathrm{C}(6)$.

Total RNA was prepared from $1 \times 10^{7}$ hybridoma cells using the acid phenol guanidine method (7). RT-PCR reactions were performed using reagents from Invitrogen Ltd (Paisley, Strathclyde, UK). Sense and antisense primers including additional restriction endonuclease site sequences to facilitate cloning of PCR products were synthesised according to Kettleborough et al. (8). The complete panel of heavy chain (HC) and light chain (LC) gene primers were used in RT-PCR and the products cloned into pUC18 and sequenced as described before (9). Variable (V) region sequences were compared with available sequences of mouse immunoglobulin genes using Ig blast (http://www. ncbi.nlm.nih.gov/igblast/).

A recombinant Fab of M21-OH5 was produced in Escherichia coli using a previously described method (10). The HC and the LC RT-PCR products were cloned into Immunozap $\mathrm{H} / \mathrm{L}$ vector (Stratagene Europe, Amsterdam, The Netherlands) under the lacZ promoter and the cloning confirmed by sequencing. M21-OH5 Fab was expressed in HB2151 cells (Amersham Biosciences) using conditions as described previously (10). M21-OH5 Fab preparations contained in the bacterial cell extract in PBS with $1 \%$ Triton $\mathrm{X}$ 100 and $1 \mathrm{mmol} / \mathrm{l}$ phenylmethylsulphonylfluoride (PMSF) were analysed for 21-OH binding activity as described before (6).

The characteristics of the 21-OH MAbs studied, i.e. the isotype, the LC type, 21-OH binding affinity and the epitopes recognised are summarised in Table 1. The effects of MAb F(ab')2 on binding of 21$\mathrm{OH}$ autoantibodies to ${ }^{125} \mathrm{I}-21-\mathrm{OH}$ was tested in an immunoprecipitation assay as described before $(6,11)$ using reagents from RSR Ltd (Cardiff, UK) (Table 1). In addition, the effects of the MAbs on 21-OH enzyme activity were studied by incubating MAb IgGs with the 21-OH preparations (12). In these experiments, microsomes prepared from 21-OH expressing yeast (0.5 $\mu \mathrm{g}$ protein) were incubated with IgG preparations $(100 \mu \mathrm{g}$ in $50 \mu \mathrm{l} \mathrm{PBS})$ at $0{ }^{\circ} \mathrm{C}$ for $16 \mathrm{~h} .21-\mathrm{OH}$ enzyme activity in microsomal preparations was then measured in terms of conversion of $\left[{ }^{3} \mathrm{H}\right]$ progesterone to deoxycorticosterone as described before $(12,13)$.
Control experiments using IgGs obtained from a 21$\mathrm{OH}$ antibody (Ab)-positive patient with autoimmune Addison's disease and from healthy blood donors were also carried out, as described previously (12). MAb (IgG preparation) reactive with human acetylcholine receptor (4B7-2C4; RSR Ltd) was used as a negative control.

\section{Modelling of 21-OH and 21-OH MAbs}

The amino acid (aa) sequence of human steroid 21-OH (14) was taken from the SWISSPROT/TrEMBL data base (http://www.ebi.ac.uk/swissprot/). A search for conserved residues with homologous cytochrome p450 proteins was carried out by BLAST (15). The crystallographic structure of rabbit cytochrome p450 $2 \mathrm{c} 5 / 3 \mathrm{LVdH}(2 \mathrm{c} 5 / 3)$ which has $29.2 \%$ amino acid sequence identity with human steroid 21-OH was used as a homologue for the structural modelling (16-18). The homologue's structure lacks a transmembrane helix (aa 3-21) that had been deleted to increase the solubility of the protein for crystallisation purposes (17). Several steps were followed in order to obtain the preliminary alignment. First, an alignment between rabbit cytochrome p450 2c5/3 and 21-OH with the program FUGUE (19) was carried out. Then, an alignment between $21-\mathrm{OH}$ and its protein family using a BLAST search followed by an alignment between the P450 family from the HOMSTRAD $(20,21)$ database and the previously produced $21-\mathrm{OH}$ family alignment was carried out. A combination of these alignments allowed us to obtain a final alignment. The program SCORE (22) produced the core of the protein. The program CODA (23) was used to obtain the loops not present in the SCORE output. A final energy-geometry minimisation was done by Tripos force field (24). The model was verified with PROCHEK (25), VERIFY3D (26) and JOY (27) and the alignment modified as required. This process was repeated three times. Three loops of the structure were modified using the SYBYL loop database (24) and a final minimisation was carried out. The transmembrane helix of 21-OH (aa 3-21) was modelled using the N-terminal fusion peptide of HIV-1 gp41 (28) as a homologue. The haem group taken from rabbit cytochrome p450 2c5/3 was incorporated using the program MNYFIT (29).

21-OH MAb V region sequences were used to search for the most suitable templates from the HOMSTRAD

Table 1 Characteristics of mouse MAbs to $21-\mathrm{OH}$.

\begin{tabular}{|c|c|c|c|c|}
\hline 21-OH MAb & Isotype & Affinity constants & Epitope region & Inhibition of ${ }^{125} \mathrm{I}-21-\mathrm{OH}$ binding to $21-\mathrm{OH} \mathrm{AAb}^{*}$ \\
\hline $\begin{array}{l}\text { M21-OH1 } \\
\text { M21-OH3 } \\
\text { M21-OH5 }\end{array}$ & $\begin{array}{l}\lg G 2 a / \kappa \\
\lg 1 / \kappa \\
\lg 1 / \kappa\end{array}$ & $\begin{array}{l}7.0 \times 10^{8} \mathrm{l} / \mathrm{mol} \\
2.6 \times 10^{8} \mathrm{l} / \mathrm{mol} \\
2.3 \times 10^{7} \mathrm{l} / \mathrm{mol}\end{array}$ & $\begin{array}{l}391-405 \text { aa } \\
406-411 \text { aa } \\
335-339 \text { aa }\end{array}$ & $\begin{array}{r}0-50 \%(n=25) \\
27 \%-75 \%(n=25) \\
35 \%-92 \%(n=25)\end{array}$ \\
\hline
\end{tabular}

*The range of inhibitions obtained with 25 different $21-\mathrm{OH}$ autoantibody (AAb) positive sera is shown. See reference (6) for details. 
$(20,21)$ and BLAST (15) databases. Alignments were obtained using FUGUE (19). The MAb models were built using MODELLER (30) and RAPPER (31, 32) and validated with PROCHECK (25) and VERIFY3D (26). HBPLUS was used for hydrogen bond definition (33). Program HERA was used for topology calculation and secondary structure representation (34). The interface solvent accessible surface area (ASA) was calculated using the Richmond algorithm (35) based on the Lee and Richards definition (36). The contact residues were defined as the residues that possess an ASA that decreased by more than $1 \AA^{2}$ on complexation (37). GRASP (38) was used to study the electrostatic potential surfaces of $21-\mathrm{OH}$ and the combining regions of MAb variable regions.

Protein-protein docking was carried out using Global Range Molecular Matching (GRAMM) methodology (39). The graphical program RASMOL (40) was used for visualisation of protein-protein complexes and the program MNYFIT (29) was used for superimposing the co-ordinates of peptide chains.

\section{Results}

\section{1-OH MAb characteristics}

As shown in Fig. 1, the 21-OH MAb M21-OH5 but not M21-OH1 or M21-OH3 had an effect on 21-OH enzyme activity relative to the effect of a control MAb IgG. Briefly, in the presence of $100 \mu \mathrm{g}$ IgGs from M21$\mathrm{OH} 1, \mathrm{M} 21-\mathrm{OH} 3$ or $\mathrm{M} 21-\mathrm{OH} 5$ the remaining 21-OH enzyme activity was $88.8 \% \pm 24 \%$ (mean \pm S.D.; $n=5$ ), $86.7 \% \pm 7.6 \%$ (mean \pm S.D.; $n=6$ ) and $48.5 \% \pm 8.3 \%$ (mean \pm S.D.; $n=6$ ) respectively. This can be compared with $86.5 \% \pm 10.6 \%$ (mean \pm S.D.; $n=6$ ) of the remaining 21-OH enzyme activity in the presence of $100 \mu \mathrm{g}$ control MAb IgG. The difference in 21-OH enzyme

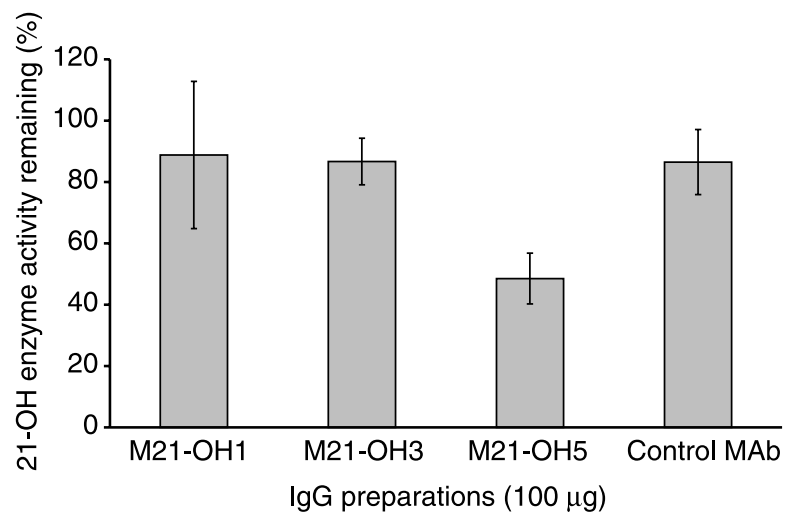

Figure 1 Effect of different IgG preparations on 21-OH enzyme activity. $\mathrm{M} 21-\mathrm{OH} 1, \mathrm{M} 21-\mathrm{OH} 3$ and $\mathrm{M} 21-\mathrm{OH} 5$ are mouse monoclonal antibodies to $21-\mathrm{OH}$. Control Mab, mouse monoclonal antibody to the acetylcholine receptor. Results are shown as means \pm S.D. of enzyme activity after incubation with test IgG $(100 \mu \mathrm{g})$; see text for details. activity remaining in the presence of M21-OH5 IgG compared with control MAb IgG was statistically significant $(P<0.001$; Student's $t$-test $)$ but this was not so in the presence of M21-OH1 $(P=0.88)$ and M21$\mathrm{OH} 3(P=0.98)$. In the same series of experiments, incubation of $21-\mathrm{OH}$ with $100 \mu \mathrm{g}$ IgG from a $21-\mathrm{OH}$ autoantibody-positive patient reduced 21-OH enzyme activity to $15 \%$ of the level observed after incubation with $100 \mu \mathrm{g}$ healthy blood donor IgG.

The $\mathrm{V}$ regions of the $\mathrm{HC}$ and $\mathrm{LC}$ of each 21-OH MAb were analysed as shown in Tables 2 and 3. M21-OH1 $\mathrm{HC}$ genes were derived from the J558.47 germline, JH genes were from $\mathrm{JH} 3$ and the $\mathrm{D}$ gene could not be assigned. The LC genes were from $\mathrm{cr} 1$ and JK2 germlines. M21-OH3 used VH7183.9, DSP2.6, JH3 (the HC genes) and 21-12 and JK2 (the LC genes) germlines. M21-OH5 used VHGa155.1, DSP2.6 and JH3 germlines for the $\mathrm{HC}$ and 8-30 and JK2 germlines for the LC. The homology of the $\mathrm{V}$ region genes to their respective germlines as well as an analysis of replacement/ silent (R/S) mutation ratio and amino acid substitution within the framework and complementarity determining regions (CDRs) are shown in Table 2. The aa sequences of HC and LC CDRs (41) of the three 21$\mathrm{OH}$ MAbs are shown in Table 3.

Extracts from E. coli transformed with M21-OH5 HC and LC sequences obtained from RT-PCR carried out on hybridoma RNA showed 21-OH binding activity. In particular, $9.1 \%$ binding of ${ }^{125}$ I-labelled $21-\mathrm{OH}$ was observed with Fab preparations contained in undiluted bacterial extract, $7.8 \%$ with Fab preparations diluted 1:10 and 4.5\% with Fab preparations diluted 1:100 (Fig. 2). Hybridoma-derived M21-OH5 IgG at concentrations of $1 \mu \mathrm{g} / \mathrm{ml}, \quad 0.1 \mu \mathrm{g} / \mathrm{ml}$ and $0.01 \mu \mathrm{g} / \mathrm{ml}$ showed $12.1 \%, 7.0 \%$ and $4.2 \%$ binding of ${ }^{125} \mathrm{I}-21-\mathrm{OH}$ respectively (Fig. 2). Control recombinant Fab with the thyrotrophin (TSH) receptor antibody activity prepared using the same method as M21-OH5 Fab (10) showed approximately $3 \%$ binding of ${ }^{125}$ I-labelled 21 $\mathrm{OH}$ at different dilutions. In addition, undiluted and diluted 1:3 preparations of recombinant $\mathrm{M} 21-\mathrm{OH} 5$ Fab inhibited binding of M21-OH5 IgG to ${ }^{125} \mathrm{I}-21-\mathrm{OH}$ by $64 \%$ and $49 \%$ respectively. Control Fab preparations at similar dilutions showed approximately 20\% inhibition of M21-OH5 IgG binding to 21-OH (data not shown).

\section{1-OH modelling}

The validation parameters of the $21-\mathrm{OH}$ model after incorporation of the transmembrane helix and the haem group are shown in Table 4 . The overall fold of 21-OH can be divided into two domains, a helix-rich domain that contains the haem group and a $\beta$-sheet domain consisting mainly of antiparallel $\beta$ strands which is involved mostly in interaction with the membrane (Fig. 3A). A core structure, conserved within the P450 cytochrome family, which is formed by a 
Table 2 Characteristics of variable region genes of 21-OH MAbs.

\begin{tabular}{|c|c|c|c|c|c|c|}
\hline Antibody & Chain & Germline & $\begin{array}{c}\text { Homology at } \\
\text { oligonucleotide level }\end{array}$ & $\begin{array}{l}V(D) J ~ R / S \text { mutations ratio in } \\
\text { framework and CDRs }\end{array}$ & $\begin{array}{c}\text { No. of mutations in } \\
\text { framework (replacement) }\end{array}$ & $\begin{array}{l}\text { No. of mutations in } \\
\text { CDRs (replacement) }\end{array}$ \\
\hline \multirow[t]{3}{*}{ M21-OH1 } & $\mathrm{HC}$ & J558.47 & $96 \%$ & & & \\
\hline & & $\mathrm{D} ?$ & $0 \%$ & 3.3 & $8(6)$ & $5(4)$ \\
\hline & & $\mathrm{JH} 3$ & $100 \%$ & & & \\
\hline \multirow[t]{2}{*}{$\mathrm{M} 21-\mathrm{OH} 1$} & LC & cr1 & $95 \%$ & 2.5 & $5(3)$ & $9(7)$ \\
\hline & & JK2 & $100 \%$ & & & \\
\hline \multirow[t]{3}{*}{ M21-OH3 } & $\mathrm{HC}$ & VH7183.9 & $93 \%$ & & & \\
\hline & & DSP2.6 & $92 \%$ & 4.0 & $6(3)$ & $14(13)$ \\
\hline & & $\mathrm{JH} 3$ & $90 \%$ & & & \\
\hline \multirow{2}{*}{ M21-OH3 } & LC & $21-12$ & $97 \%$ & $6^{*}$ & 3 (3) & $3(3)$ \\
\hline & & JK2 & $100 \%$ & & & \\
\hline \multirow[t]{3}{*}{ M21-OH5 } & $\mathrm{HC}$ & VHGa155.1 & $97 \%$ & & & \\
\hline & & DSP2.6 & $67 \%$ & $7^{*}$ & $3(3)$ & $4(4)$ \\
\hline & & $\mathrm{JH} 3$ & $100 \%$ & & & \\
\hline \multirow{2}{*}{ M21-OH5 } & LC & $8-30$ & $95 \%$ & 8 & $5(4)$ & $4(4)$ \\
\hline & & JK2 & $97 \%$ & & & \\
\hline
\end{tabular}

*All mutations were replacement mutations.

Germline sequences were assigned using Ig blast, CDRs were assigned by the method of Kabat et al. (41).

four-helix bundle (D, E, I, L; Fig. 3B), two helices (J, K; Fig. 3B), two sets of $\beta$-sheets and a coil called 'meander' (K'-L loop; Fig. 3B) is present around the haem group (42). The haem-binding loop ('meander') contains the most characteristic pattern for the cytochrome $\mathrm{P} 450$ family (Phe-X-X-Gly-X-Arg-X-Cys-XGly) (PROSITE database PSO086 and the Functional Protein Sequence Pattern Database (FPSPD); http:// www-cryst.bioc.cam.ac.uk/ fpspd/: $\quad$ FPSPD06206) (43, 44) and is located before helix L with Cys 428 that serves as fifth ligand to the haem iron. The absolutely conserved motif (Glu-X-X-Arg) (FPSPD06209) in helix $\mathrm{K}$ is needed to stabilise the core structure.
The central part of helix I contains the P450 signature: Ala/Gly-Gly-X-Asp/Glu-Thr-Thr/Ser (FPSPD06208) that corresponds to the proton transfer groove of the haem group (42).

21-OH has a triangular prism shape with an edge length approximately double the thickness. The entrance to the active site of $21-\mathrm{OH}$ is present on one of the flat surfaces of the prism, referred to as the distal surface (17) whereas the binding site for the redox partner protein is present on the opposite flat surface of the prism, referred to as the proximal surface (Fig. 4). The epitopes ER1 and ER2 are positioned on the 21-OH surface distant from the

Table 3 CDRs of 21-OH MAbs assigned by the method of Kabat et al. (41).

\begin{tabular}{|c|c|c|}
\hline Antibody & Chain & CDR sequences \\
\hline $\mathrm{M} 21-\mathrm{OH} 1$ & $\mathrm{HC}$ & $\begin{array}{l}\mathrm{CDR} 1=\text { SYVMH } \\
\mathrm{CDR} 2=\text { YINPFNDDTLYNEKFKG } \\
\mathrm{CDR} 3=\mathrm{VT}\end{array}$ \\
\hline $\mathrm{M} 21-\mathrm{OH} 1$ & LC & $\begin{array}{l}\text { CDR1 }=\text { SSSQSLVRTSGNTYLD } \\
\text { CDR2 }=\text { KVSNRFP } \\
\text { CDR3 }=\text { FQGSHVPYT }\end{array}$ \\
\hline M21-OH3 & $\mathrm{HC}$ & $\begin{array}{l}\text { CDR1 }=\text { TFTMS } \\
\text { CDR2 }=\text { AIKGYGSSTFYTDSVKG } \\
\text { CDR3 }=\text { DGYDGGFAY }\end{array}$ \\
\hline M21-OH3 & LC & $\begin{array}{l}\text { CDR } 1=\text { RASKSVSTSGYSYMH } \\
\text { CDR2 }=\text { LVSNLES } \\
\text { CDR3 }=\text { QHIREAYT }\end{array}$ \\
\hline M21-OH5 & $\mathrm{HC}$ & $\begin{array}{l}\text { CDR1 }=\text { RYWMS } \\
\text { CDR2 }=\text { EINPDSSTINYTPSLKD } \\
\text { CDR3 }=\text { PGDYGYDWFAY }\end{array}$ \\
\hline M21-OH5 & LC & $\begin{array}{l}\text { CDR1 }=\text { KSSQSLLYRSNQKNYLA } \\
\text { CDR2 }=\text { WASTRES } \\
\text { CDR3 }=\text { QQYYDFPYT }\end{array}$ \\
\hline
\end{tabular}

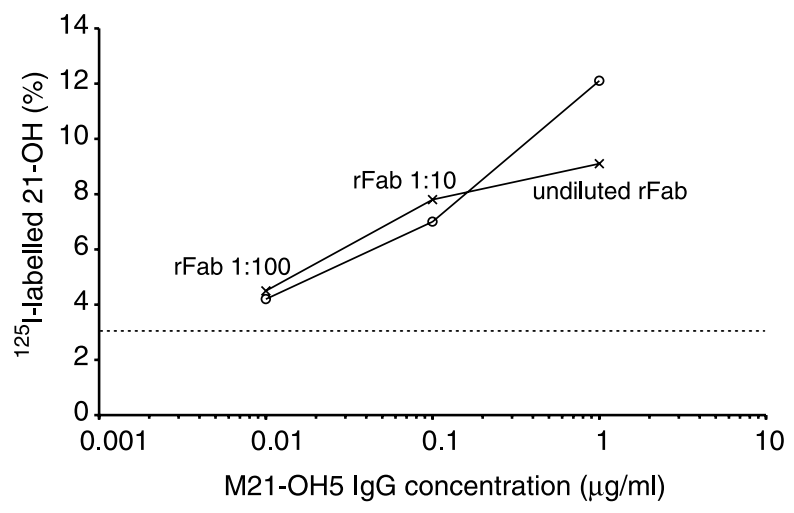

Figure 2 Binding of M21-OH5 IgG or recombinant M21-OH5 $\mathrm{Fab}$ to ${ }^{125}$ /-labelled $21-\mathrm{OH}$ in an immunoprecipitation assay (6). Open circles denote M21-OH5 lgG, crosses denote recombinant (r) M21-OH5 Fab tested undiluted, diluted 1:10 and diluted 1:100 in the assay buffer (6). The horizontal dashed line indicates the mean binding of control recombinant Fab with the TSH receptor binding activity (10). 
Table 4 Validation parameters obtained for the models of $21-\mathrm{OH}$ and 3 MAbs.

21-OH M21-OH1 M21-OH3 M21-OH5

\begin{tabular}{|c|c|c|c|c|}
\hline \multicolumn{5}{|l|}{ Ramachandran plot } \\
\hline aa in favoured regions & $73.4 \%$ & $93.2 \%$ & $89.2 \%$ & $93.3 \%$ \\
\hline aa in allowed regions & $26.7 \%$ & $6.2 \%$ & $10.6 \%$ & $6.7 \%$ \\
\hline aa in disallowed regions & $0.0 \%$ & $0.5 \%$ & $0.3 \%$ & $0.0 \%$ \\
\hline \multicolumn{5}{|l|}{ PROCHECK } \\
\hline Overall $\mathrm{G}$ factor & -0.03 & -0.11 & -0.10 & -0.08 \\
\hline Bad contacts & 6 & 6 & 8 & 10 \\
\hline $\begin{array}{l}\text { Number of off graph } \\
\text { geometrical values }\end{array}$ & 2 & 0 & 1 & 0 \\
\hline \multicolumn{5}{|l|}{ VERIFY3D } \\
\hline Top value & +0.75 & +0.75 & +0.81 & +0.76 \\
\hline Lower value & -0.45 & +0.14 & +0.14 & +0.11 \\
\hline Number of residues & 23 & 0 & 0 & 0 \\
\hline
\end{tabular}

substrate binding site and the redox partner protein binding site (Fig. 4). ER3 is placed away from the positions of ER1 and ER2 on the surface of 21-OH but close to the binding site of the redox partner protein (Fig. 4).

The active site of $21-\mathrm{OH}$ is characterised by residues able to bind the haem group through hydrogen bonds or salt bridges - Lys120, His365, Arg426 (main chain interaction) and the fifth iron ligand Cys428 (Fig. 5). The haem group is positioned in three points by hydrogen bonds and salt bridges: the iron atom that interacts with Cys428, one carboxylic group of the haem group that interacts with Lys120 and the other carboxylic group that interacts with Arg426 and His365. Two different channels which allow substrate access to the active site of $\mathrm{P} 450$ enzymes have been defined (18, 45-47). Channel 1 is formed by a loop (BC) and 2 helices (G and I) (18, 47). In our model, residues Arg91, Pro92, Leu109, Gly110, Trp116 (from the BC loop), Arg366 (from strand 4 of sheet 1) and Arg426 (before helix L) define the open end of channel 1 at the bottom of the structure of 21-OH and close to the membrane (Figs. $3 \mathrm{~B}$ and $4 \mathrm{~A}$ ). Channel 2 (on the distal flat surface) is a long hydrophobic channel lined with mostly non-aromatic hydrophobic residues (18, 45-47) (Fig. 4A). This corresponds to helix A', the FG loop and residues from the turn formed by sheet 4 (a long loop at the $\mathrm{C}$-terminus) which form the channel 2 entrance $(18,45-47)$. In our model, residues Lys199 (from the FG loop), Glu294, Thr295 (from the helix I), Leu471 and Lys472 (from the turn of sheet 4) form the entrance of channel 2 (Figs. 3B and 4A).

The electrostatic potential of the proximal surface of the model of $21-\mathrm{OH}$ is shown in Fig. $6 \mathrm{~A}$ and there is a highly positively charged groove in the centre of the surface consistent with a binding site for the highly negatively charged flavin mononucleotide (FMN)-binding domain of the NADPH-cytochrome p450 oxidoreductase (CPR) (see Discussion and (48)).
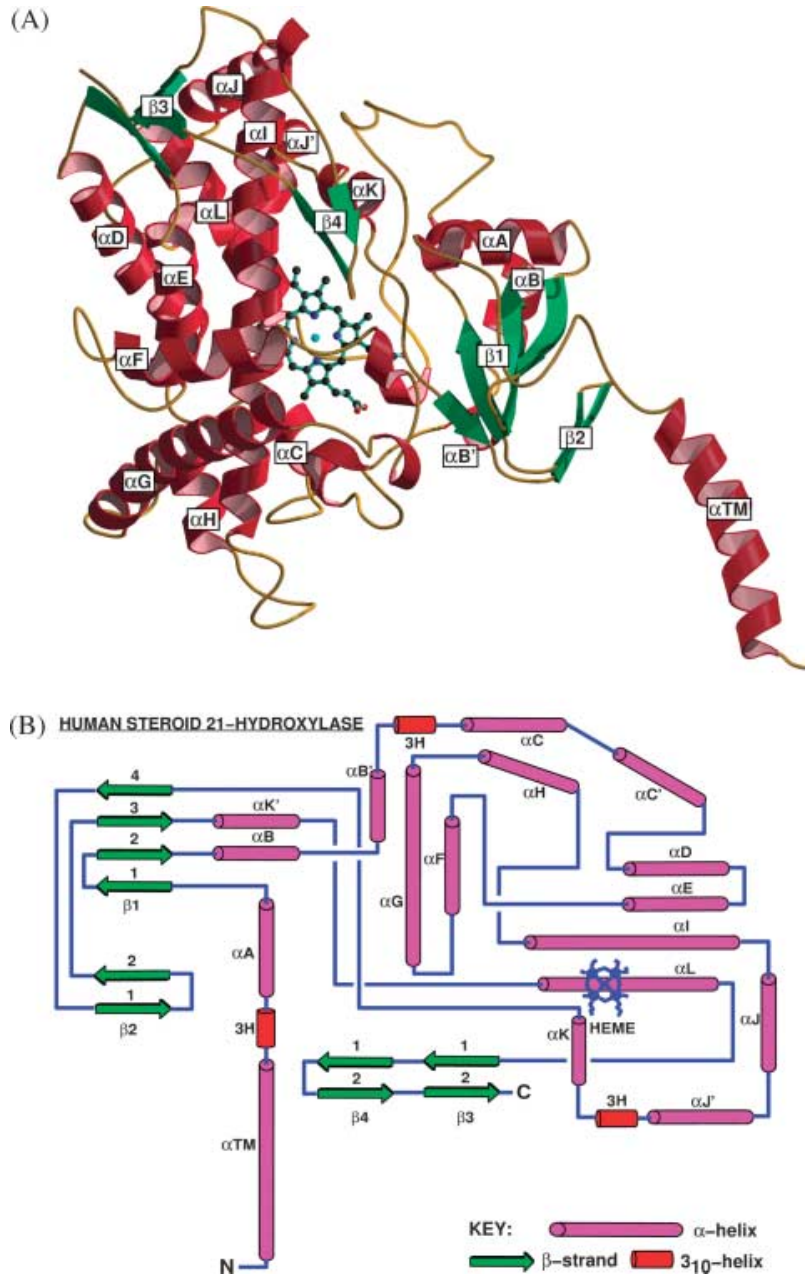

Figure 3 (A) Cartoon representation of the $21-\mathrm{OH}$ model. Helices are in red and are marked $\alpha A$ to $\alpha \mathrm{L}$ with the transmembrane helix as $\alpha \mathrm{TM}$, beta strands are in green with the beta-sheets marked $\beta 1$ to $\beta 4$. In the haem group the carbon atoms are in black, oxygen atoms in red, nitrogen in dark blue and the iron in light blue. (B) Schematic representation of the secondary structure of the model of 21-OH based on the program HERA (34). Alpha helices are labelled $\alpha \mathrm{A}$ to $\alpha \mathrm{L}, 3_{10}$ helices are labelled $3 \mathrm{H}$, beta-sheets are labelled $\beta 1$ to $\beta 4$ and each $\beta$-strand is numbered with each $\beta$-sheet. The haem group position is shown as well as the $\mathrm{N}$ - and C-termini.

\section{Modelling of 21-OH MAbs}

The antibody structure with identification number 1yec (Protein Data Bank; http://www.rcsb.org/pdb/) (49) was chosen for building the framework of M21-OH1 Fab, 1hyx (50) was chosen for the LC variable region and $1 \mathrm{i} 8 \mathrm{~m}$ (51) for the $\mathrm{HC}$ variable region. Antibody structure 1hi6 (52) was used for modelling of M21-OH1 HC CDR3, which is only two residues long (Table 3). Model validation values are shown in Table 4 . The surface of the antigen binding site has five basic patches and two acidic patches with high electrostatic potential (Fig. 6B). The basic patches are centred on Lys50 and Arg54 


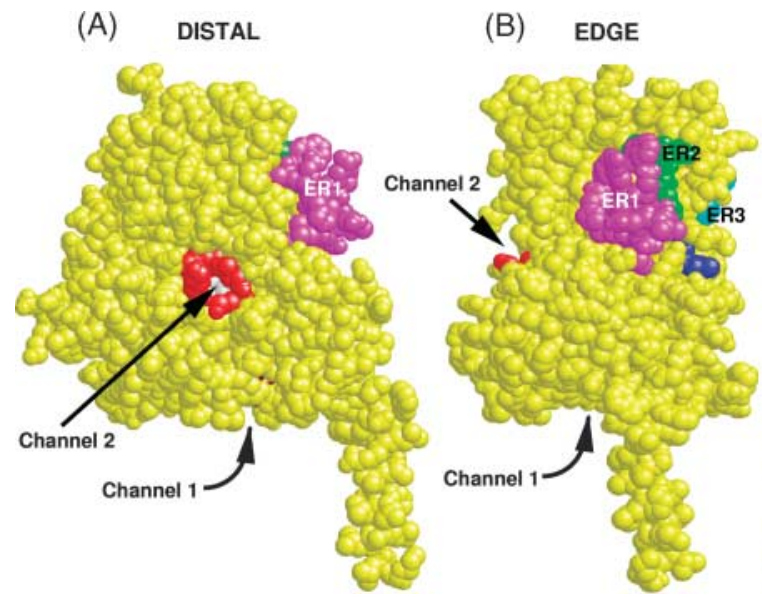

(C) PROXIMAL

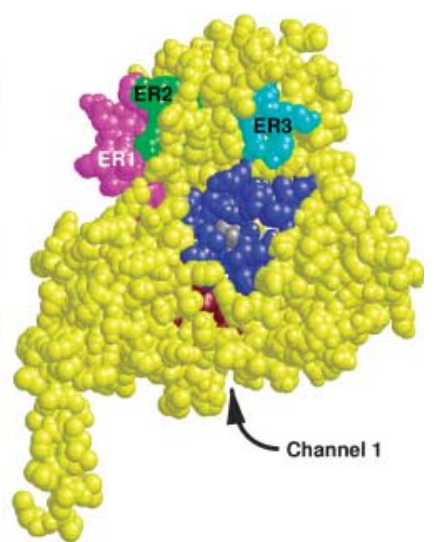

Figure 4 Space-fill representation of the model of 21-OH from three different points of view (the distal surface, the edge surface and the proximal surface). The transmembrane helix is at the bottom. The epitope ER1 (aa 391-405) is in magenta, the epitope ER2 (aa 406-411) is in green and the epitope ER3 (335-339) is in cyan. The entrance of channel 2 (aa 199, 294, 295, 471 and 472) is in red with the haem group shown in white. The entrance of channel 1 is in maroon and placed at the bottom of the structure (aa 91, 92, 109, 110, 116, 366 and 426). The redox-partner protein binds in a groove (blue) centred on Cys 428 (grey). (A) The distal flat surface of the $21-\mathrm{OH}$ molecule. (B) The edge surface of the $21-\mathrm{OH}$ molecule. (C) The proximal flat surface of the $21-\mathrm{OH}$ molecule.

(from LC CDR2) and on Lys58, Lys62 and Lys64 (from $\mathrm{HC}$ CDR2). The acidic patches are centred on residues Asp55 and Asp56 from HC CDR2. The surface of the antigen binding site of M21-OH1 presents a deep cavity in its centre flanked by aromatic residues: Tyr32 (from LC CDR1), Tyr36 and Tyr49 (from LC), Phe55 (from LH CDR2), Phe89 and Tyr96 (from LC CDR3), Phe98 (from LC), Tyr32

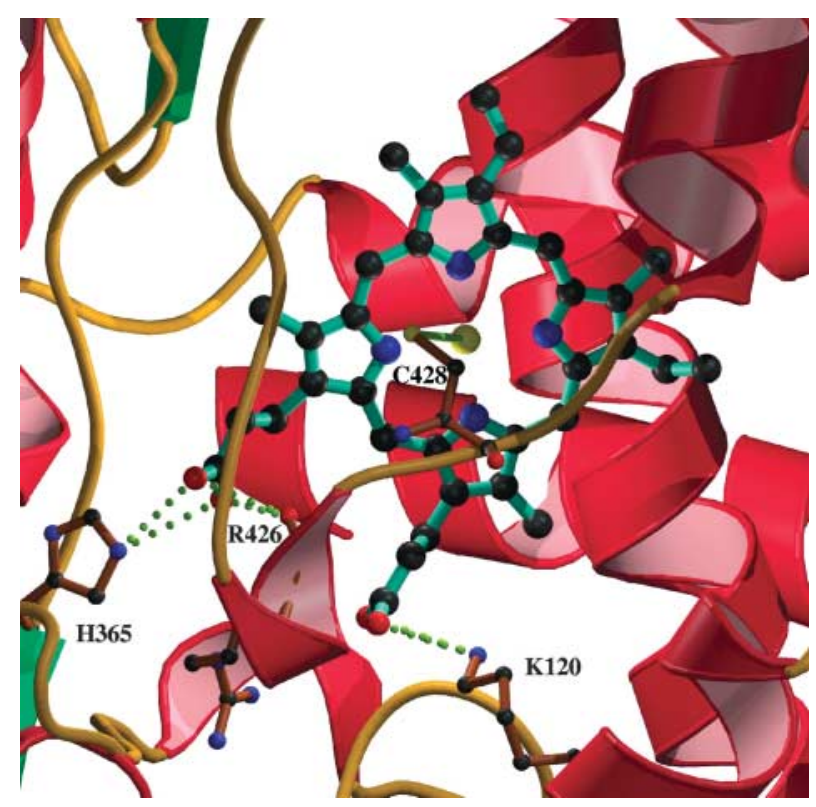

Figure 5 Representation of the active site of $21-\mathrm{OH}$. Helices are shown in red, $\beta$-strands in green and loops in yellow. Protein side chains (brown bonds) and the haem group (blue bonds) are illustrated. Hydrogen bonds are represented as dashed lines. One letter code for amino acids is used (K, Lys; H, His; R, Arg; C, Cys). (from HC CDR1), Tyr50 and Phe53 (from HC CDR2) and Trp103 (from HC) (Fig. 6B).

The structure of 1hyx antibody (50) was chosen for building of the M21-OH3 Fab framework while the structures of 1 bln (53) and 32c2 (54) antibodies were chosen for building the variable $\mathrm{HC}$ and variable LC respectively (see Table 4 for the model validation values). The surface of the antibody combining site has four basic and five acidic patches with high electrostatic potential (Fig. 6C). The basic patches are centred on Lys27 (from LC CDR1), Arg92 (LC CDR3), Lys52 (from HC CDR2) and Lys64 (HC CDR2). The acidic patches are centred on Glu55 (from LC CDR2), Glu93 (LC CDR3), Asp61 (HC CDR2), Asp95 (HC CDR3) and Asp98 (HC CDR3). There are ten aromatic residues homogeneously distributed in the combining site. The surface of the combining site is highly irregular (Fig. 6C).

The structure of 1sbs antibody (55) was chosen for building the framework of the M21-OH5 Fab and its LC variable region, while $2 \mathrm{fbj}$ antibody (56) structure was used for building the $\mathrm{HC}$ variable region except for $\mathrm{HC}$ CDR3. M21-OH5 HC CDR3 was modelled on the structure of 1hil antibody (57) (see Table 4 for the model validation values). The surface of the antigen binding site has six basic and seven acidic patches with high electrostatic potential (Fig. 6D). The basic patches are centred on Lys24, Arg27E and Lys30 (from LC CDR1), Arg54 (LC CDR2), Arg31 (HC CDR1) and Lys64 (HC CDR2). The acidic patches are centred on Glu55 (from LC CDR2), Asp93 (LC CDR3), Glu50, Asp53, Asp65 (from HC CDR2), and Asp97 and Asp100I (from HC CDR3). An aromatic core is formed by LC tyrosines $27 \mathrm{D}, 32$, 91 and 96 . The surface of the combining site is highly irregular and presents a highly acidic patch in its centre (Fig. 6D). 

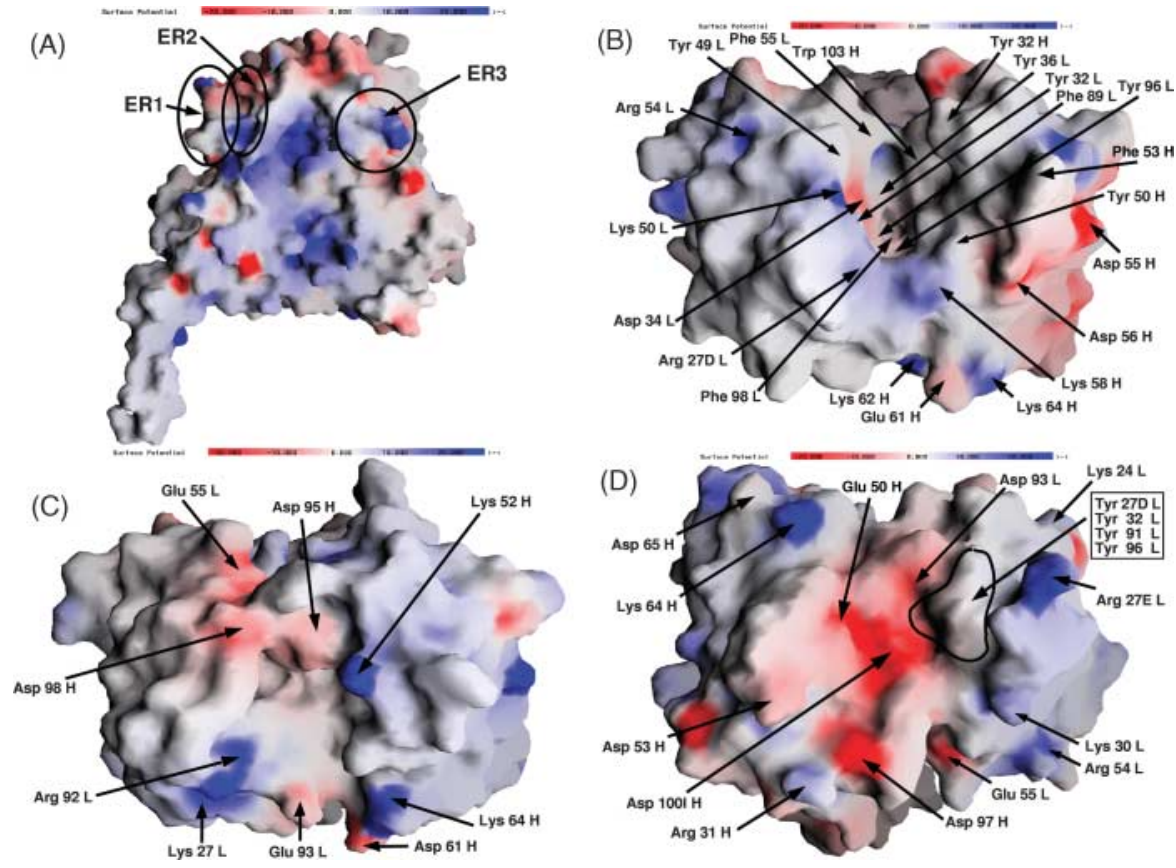

Figure 6 Electrostatic potential of the proximal surface of the model of 21-OH with $(A)$ epitope regions ER1 to ER3 marked, and (B-D) the surface of the antigen binding site of (B) M21-OH1, (C) M21-OH3 and (D) M21-OH5. L indicates amino acid from the light chain, $\mathrm{H}$ indicates amino acid from the heavy chain. The circled area in (D) contains four tyrosine residues as indicated in the box. The acidic patches are shown in red; the basic patches are shown in blue.

\section{Analysis of the complexes between 21-OH and 21-OH MAbs}

Complexes between M21-OH1 and 21-OH obtained in protein-protein docking experiments were studied consecutively in the order produced by the program GRAMM, and the complex which showed the best interaction between the 21-OH epitope ER1 (aa 391-405) and M21-OH1 was selected. In the complex, 39 residues from 21-OH interact with 43 residues from M21-OH1. Nine residues from LC CDR1 of M21-OH1, seven from LC CDR2, five from LC CDR3, four from HC CDR1 and seven from HC CDR2 are involved in the interaction. Phe53 from HC CDR2 and Thr27E from LC CDR1 show strong interactions of $6.8 \%$ and $6.0 \%$ of the change in interface ( $\triangle \mathrm{ASA})$ respectively. Five 21-OH sequence segments are involved in the interface in the complex with M21-OH1. The fifth segment includes aa $389-399$ and contributes to $24.6 \%$ of the interface $\triangle$ ASA. Arg 75 and Gln53 from 21-OH are involved in strong interactions with M21-OH1 (10.7\% and $9.6 \%$ of the interface $\triangle$ ASA respectively). In the complex, the total ASA buried in the interface of 21$\mathrm{OH}$ is $1479 \AA^{2}$ and $1486 \AA^{2}$ for M21-OH1. There are $66.7 \%$ and $72.1 \%$ polar residues from $21-\mathrm{OH}$ and M21-OH1 respectively and ten hydrogen bonds in the complex interface, two of these hydrogen bonds are in the region corresponding to the ER1.

In the case of M21-OH3, the complex with the best interaction between $\mathrm{M} 21-\mathrm{OH} 3$ variable region and the 21-OH epitope ER2 (aa 406-411) was chosen. In the complex, 31 residues from $21-\mathrm{OH}$ interact with 32 residues from M21-OH3 ( 5 are from LC CDR1, 6 from LC CDR2, 1 from LC CDR3, 3 from HC CDR1, 8 from $\mathrm{HC}$ CDR 2 and 5 from $\mathrm{HC}$ CDR 3 ). Tyr 53 from HC CDR 2 and Tyr97 from HC CDR 3 of M21-OH3 produce strong interactions of $11.6 \%$ and $11.5 \%$ of the interface $\triangle$ ASA respectively. In $21-\mathrm{OH}$, the interface is formed by four sequence segments involving different residues between aa 316 and 435 . The third segment (aa 395 to 417) includes the whole sequence of ER2 (aa 406-411) which accounts for $14.3 \%$ of the interface $\triangle$ ASA. In the complex between 21-OH and M21$\mathrm{OH} 3$, the total ASA of 21-OH buried in the interface is $1217 \AA^{2}$ and of $\mathrm{M} 21-\mathrm{OH} 3$ interface is $1143 \AA^{2}$. There are $68.8 \%$ and $74.2 \%$ polar residues from 21 $\mathrm{OH}$ and $\mathrm{M} 21-\mathrm{OH} 3$ respectively, and 26 hydrogen bonds and one salt bridge in the complex interface. Six out of twenty-six hydrogen bonds in the complex interface are present in the region corresponding to the ER2.

In the case of M21-OH5, the complex with the best interaction with the epitope ER3 (aa 335-339) was selected (Fig. 7). In the complex, 17 residues from 21$\mathrm{OH}$ interact with 16 residues from M21-OH5. Six residues from LC CDR1 of M21-OH5, one from LC CDR2, two from LC CDR3, one from HC CDR1 and five from HC CDR 3 are involved in the interaction. Tyr98 from HC CDR3 and Arg27E from LC CDR1 show strong interactions of $17.0 \%$ and $15.1 \%$ of the interface $\triangle$ ASA respectively. In $21-\mathrm{OH}$, the interface is formed by two sequence segments. The first segment includes residues aa 336-339 (almost the entire ER3; aa 335339 ) which contribute to $25.7 \%$ of the interface $\Delta$ ASA. Arg341 and Lys337 of 21-OH are involved in strong interactions $(20.3 \%$ and $16.6 \%$ of the interface $\triangle$ ASA respectively). The total ASA buried in the 


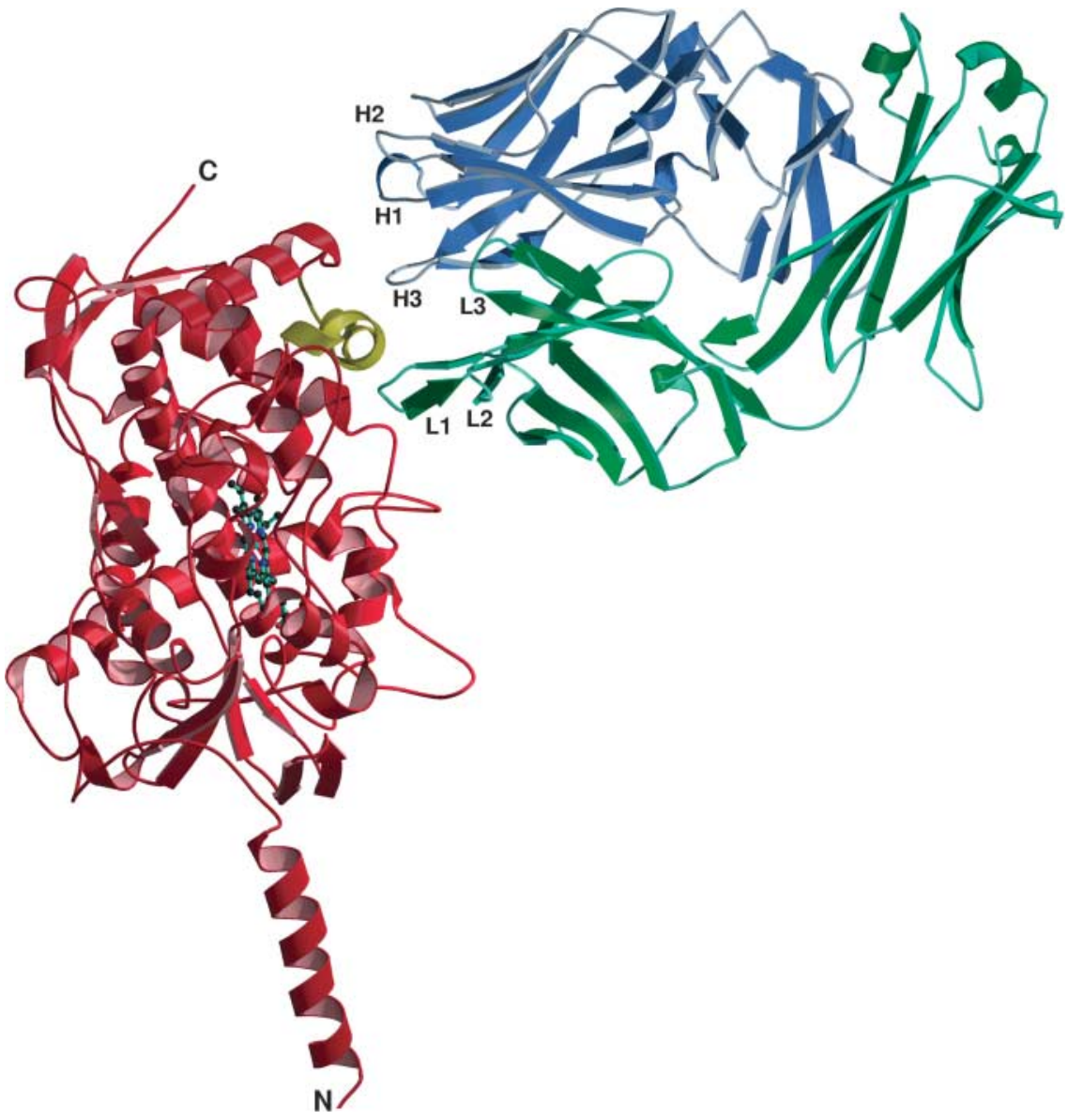

Figure 7 Structural model of the 21$\mathrm{OH}-\mathrm{M} 21-\mathrm{OH} 5 \mathrm{Fab}$ complex. Antibody heavy chain is shown in blue, light chain in green, $21-\mathrm{OH}$ in red. The haem group (blue bonds) is illustrated. The epitope ER3 (aa 335-339) is shown in yellow. The $\mathrm{N}$ - and C-termini of 21-OH are marked as $\mathrm{N}$ and $\mathrm{C}$ respectively and the variable regions of M21-OH5: L1 = LC CDR1, L2 = LC $\mathrm{CDR} 2, \mathrm{~L} 3=\mathrm{LC}$ CDR3, $\mathrm{H} 1=\mathrm{HC}$ $\mathrm{CDR} 1, \mathrm{H} 2=\mathrm{HC}$ CDR2 and $\mathrm{H} 3=\mathrm{HC}$ CDR3 are indicated (see text for details). interface of $21-\mathrm{OH}$ is $652 \AA^{2}$ while for M21-OH5 it is $723 \AA^{2}$. There are $64.7 \%$ and $93.8 \%$ polar residues from $21-\mathrm{OH}$ and $\mathrm{M} 21-\mathrm{OH} 5$ respectively and ten hydrogen bonds and one salt bridge in the complex interface. Three out of ten hydrogen bonds found in the complex interface are produced by the ER3.

\section{Discussion}

We have built a comparative model of the structure of 21-OH based on the structure of rabbit cytochrome p450 2c5/3 (16-18). The validation parameters for our model (Table 4) were consistent with previously described criteria for optimum positions of residues in the structure (25-27) but VERIFY 3D showed an area with negative values between aa 205-225. This aa region $205-225$ of $21-\mathrm{OH}$ is involved in membrane binding and corresponds to the region where several mutations had been introduced into the sequence of the rabbit P450 2c5/3 in order to avoid aggregation and to facilitate crystallisation (17). The native sequence between aa 205 and 225, which is not associated with the membrane in our model resulted in negative values in VERIFY 3D analysis (26).
The template (the structure of rabbit P450 2c5/3) we used had its transmembrane helix (aa 3 to 21) absent (the corresponding part of the sequence was removed from the protein to avoid aggregation during crystallisation) (17). Consequently, the N-terminal peptide of HIV-1 gp41 (28) was chosen in order to obtain the structure of the transmembrane helix of 21-OH in our model and this peptide adopts a transmembrane helix structure with a hydrophobicity profile similar to that of the helical sequence of the transmembrane section of $21-\mathrm{OH}$.

A typical $\mathrm{P} 450$ enzyme structure contains four $\beta$-sheets $(\beta 1-\beta 4)$ and approximately $13 \alpha$-helices (42). Some structures of members of the P450 enzyme family also contain the $\beta 5 \beta$-sheet (42). The more variable structural elements are helices A, B, B', F, G, H, K', $\beta$-sheets $\beta 3, \beta 4$, and the loops (42). In our model of $21-\mathrm{OH}$, all helices belonging to the structurally conserved core of the $\mathrm{P} 450$ family (i.e. helices D, E, I, L, J and K) are present (Fig. 3B) (42). Also present are the two conserved $\beta$-sheets $\beta 1$ and $\beta 2$ as well as the coil 'meander' (loop between helices K' and L) which is highly conserved in the structure and is located on the proximal face (Fig. 3B) (42). The only structural difference between $21-\mathrm{OH}$ and the conserved 
P450 structural core is that 21-OH $\beta 1$ has only four strands instead of five (Fig. 3B).

The non-conserved or variable regions of $\mathrm{P} 450$ enzymes together with some well-conserved regions are usually associated with substrate binding and redox partner binding $(58,59)$. The variable regions associated with substrate binding are helices A, B, B', $\mathrm{F}$ and $\mathrm{G}$ and their adjacent loops and include the substrate recognition sites (SRS) identified by Gotoh (60) in the CYP2 family. Loops B-B' and B'-C line the active site (SRS-1), and helices $\mathrm{F}$ and $\mathrm{G}$ and the loop between them form part of the access channel 2 and ceiling of the active site (SRS-2 and SRS-3). The loop at the end of $\beta 4$ protrudes into the active site (SRS6 ), as does the region at the N-terminus of the fourth strand of $\beta 1$ (SRS-5), which in 21-OH contains His 365 that binds one of the carboxylic groups of the haem group (42). Finally, the highly conserved central portion of helix I (SRS-4) contributes to formation of the active site.

$\mathrm{NADPH}$-cytochrome $\mathrm{P} 450$ oxidoreductase (CPR) is a flavoprotein composed of four domains (48). The flavin mononucleotide (FMN)-binding domain interacts with the proximal surface of $21-\mathrm{OH}$ and it has been shown that the binding site of the FMN-binding domain is highly negatively charged (48). Analysis of the crystal structure of the BM3-FMN complex (61) shows that the FMN residues from the $\alpha_{1}$-helix and the outer FMN-binding loop interacts with the C- and L-helices and the peptide that precedes the haem-binding loop (the 'meander') of the P450. These interaction areas in $\mathrm{P} 450 \mathrm{BM} 3$ correspond to a highly positively charged groove in our 21-OH model (Fig. 6A) consistent with this groove being the binding site for the highly negatively charged FMN-binding domain (48).

A decade ago, Lin et al. (62) described models of human steroid 17-alpha and 21-hydroxylase based on the structure of bacterial P450cam from Pseudomonas putida. There are substantial differences between the soluble bacterial P450cam and membrane-bound mammalian P450 enzymes of the endoplasmic reticulum (63). The Lin et al. model was built by amino acid substitution of the backbone, and the side chains were positioned manually. In contrast, to build our model, we have used the program SCORE (22) for modelling the core of the protein and CODA (23) for modelling the loop regions not present in the SCORE output. Auchus and Miller have constructed a model of human P450c1 7 (17 $\alpha$-hydroxylase/17,20-lyase) (64) using the bacterial enzyme $\mathrm{P} 450 \mathrm{BMP}$ as a template. The model scored well for side chain parameters, bad contacts and distortion of atom geometries, but less well for main chain parameters; $73.4 \%$ of residues were placed in the favoured regions of the Ramachandran plot (the same value was obtained for our model). However, in the Auchus and Miller model some undisclosed residues were present in disallowed regions of the Ramachandran plot. In contrast, in our model of 21-OH none of the residues are present in disallowed regions of the Ramachandran plot. The overall G-factor of the Auchus and Miller model is - 0.41 (64) compared with -0.03 in our model; overall G-factor scores should be above -0.5 and values below -1.0 may need investigation (25). In the P450c17 model proposed by Auchus and Miller (64), Cys442 (Cys428 in 21$\mathrm{OH})$ acts as a ligand of the haem group and Arg440 (Arg426 in 21-OH) forms a hydrogen bond with one of the carboxylic groups of the haem group. The inability of the P450c17 mutant His373Leu to bind haem was explained on the basis that in the Auchus and Miller model His373 (His365 in 21-OH) did not interact with the haem group and the mutation creates a global alteration of the structure. In our model of 21-OH, however, His 365 produces a hydrogen bond with one of the carboxylic groups of the haem group which cannot be formed after His365Leu mutation.

Lewis and Lee-Robichaud have modelled one representative member of the P450 families, CYP11, CYP17, CYP19 and CYP21, based on the structure of bacterial P450 CYP102 (65). Only two residues interacting with the haem group in addition to Cys428 were identified in their 21-OH model.

More recently, Mornet and Gibrat have published a 3D model of human P450c21 (66). The haem group in the Mornet and Gibrat model is positioned by the same amino acids as in our model. The effect of some 21-OH aa mutations on enzyme activity explained by analysis of the Mornet and Gibrat model (66) can be explained in a similar way using our model. However, the effect of Glu380Asp mutation (loss of enzyme activity) was not clearly explained by Mornet and Gibrat except that Glu380 could form a salt bridge with Arg16, Lys23 or Arg 25 (66). In our model, these three residues are positioned too far away from Glu380 to form a salt bridge in a favourable conformation. Analysis of our model suggests that the area containing Glu380 is present in the surface of an area that is close to the entrance of channel 1. The oxygen of Glu380 is 5.6 $\AA$ away from the nitrogen in Arg 366 which is present at the entrance of substrate access channel 1 resulting in charge compensation. In the case of mutation of Glu380 to aspartic acid which has a shorter side chain than glutamic acid, the distance between the charged atoms at positions 380 and 366 becomes longer. Consequently, the charges in this area are not well compensated in the mutant and 21-OH may bind too tightly to the substrate explaining the loss of enzyme activity.

The structure of rabbit cytochrome P450-2c5/3 (16-18) was the best template available for the comparative modelling of human 21-OH when we began our study. After all modelling processes were finished, the crystal structure of human cytochrome P450-2c9 (2c9) (67) became available. However, the amino acid sequence identity between $21-\mathrm{OH}$ and $2 \mathrm{c} 9$ is $27.0 \%$, slightly lower compared with the $29.2 \%$ identity 
between $21-\mathrm{OH}$ and rabbit $2 \mathrm{c} 5 / 3$. Also, the spatial coordinates of human cytochrome P450-2c8 (2c8) (25.2\% aa sequence identity with $21-\mathrm{OH})$ (68) have become available while this manuscript was in preparation. Most of the secondary structure elements obtained for our model of 21-OH are present in the crystal structure of 2c9 (67). Two $33_{10}$ helices present in 2c9 in the K'L-loop are not present in $21-\mathrm{OH}$, and a beta-hairpin ( $\beta 2$ in Fig. $3 \mathrm{~B}$ ) between strands 4 and 3 of sheet 1 in $21-\mathrm{OH}$ is not present in $2 \mathrm{c} 9$. The spatial coordinates were not available for 11 residues from the FG-loop in the rabbit 2c5/3 structure used as a template; however in our model of 21-OH there are two helices for the equivalent residues. Two helices are also present in the corresponding region of the structure of human $2 \mathrm{c} 9$, which suggests that our model of $21-\mathrm{OH}$ is consistent with the structure obtained very recently for 2c9 (67). Moreover, the rabbit 2c5/3 structure lacks a $\beta$-hairpin ( $\beta 4$ in Fig. 3B) between strands 1 and 2 of sheet 3 while our model, as well as the structure of human 2c9, present this $\beta$-hairpin $(17,67)$. The overall structure of our model of 21-OH compares well with the crystal structure of 2c9; 412 alpha carbons out of 461 from the backbones of each structure can be superimposed with less than $3.5 \AA$ deviation and this superimposition presents a root-mean-squared difference (RMSD) of $1.190 \AA$. There is only one $3_{10}$ helix in the K'L loop in the 2c8 structure (68) which is not present in the corresponding area of our $21-\mathrm{OH}$ structure. Also, a $\beta$-hairpin ( $\beta 2$ in Fig. 3B) between strands 4 and 3 of sheet 1 which is found in our model is not present in the $2 \mathrm{c} 8$ structure (68). However, the two helices placed in the FG loop of 21-OH are also present in the crystal structure of $2 \mathrm{c} 8.2 \mathrm{c} 8$ lacks the $\beta$-hairpin ( $\beta 4$ in Fig. 3B) between strands 1 and 2 of sheet $\beta 3$ and this is in contrast to the structure of 2c9 (67). There is a good agreement between the overall structure of our model of 21-OH and the crystal structure of 2c8 (68); 416 alpha carbons out of 463 from the backbones of each structure can be superimposed with less than $3.5 \AA$ deviation and this superimposition presents an RMSD of $1.167 \AA$.

The experimentally determined epitope regions (ER13 ) reactive with 21-OH MAbs (6) were identified on our structural model of $21-\mathrm{OH}$. All three were found to be present on the surface of 21-OH which is consistent with the ability of M21-OH1, M21-OH3 and M21OH5 to bind to the amino acids within these ERs (6) (Fig. 4). The $\mathrm{HC}$ and the LC $\mathrm{V}$ genes of M21-OH1, $\mathrm{M} 21-\mathrm{OH} 3$ and M21-OH5 were derived from different germline genes (Table 2). M21-OH3 and M21-OH5 had the D genes derived from the same germline (DSP2.6) whereas the D genes for M21-OH1 could not be assigned. Genes from JH3, JH4, JK1 and JK2 were used by our MAbs. Two MAbs showed high R/S mutation ratio within the $\mathrm{V}$ regions which is consistent with an antigen driven maturation (69). Analysis of the sequence of M21-OH3 revealed the absence of cysteine at position 23 of the LC. This residue is highly conserved in antibodies and is normally involved in an intra-molecular disulphide bond with the Cys residue at position 88 of the LC (70). It has been reported that recombinant antibodies could not be produced in E. coli when the cysteines 23 or/and 88 had been replaced in an $\mathrm{Fv}$ fragment (70). However, examples of functional monoclonal antibodies lacking Cys residues important for disulphide bond formation have also been described $(71,72)$.

The sequences of our MAbs were then used to build their respective comparative models. The models of these MAbs had the standard IgG Fab structures. The topography of the antigen binding site of each of the MAbs was studied and showed variations in the formation of the surface and in the distribution of negatively and positively charged amino acids. The antigen binding sites of our MAbs contained a relatively high proportion of aromatic residues which is characteristic of the combining site of antibodies $(73,74)$.

The 21-OH MAb models were used in protein-protein docking experiments with our model of $21-\mathrm{OH}$. The complexes which showed the best fit between the MAbs and their respective epitope regions on 21-OH were selected (see Results). Analysis of these complexes revealed that 21-OH MAbs in addition to their respective epitope regions also interacted with various amino acid segments on the surface of $21-\mathrm{OH}$. However, the residues involved in the interaction within the segment containing the epitope region sequence contributed a large proportion of the total interface ASA $(24.6 \%$ in the case of $\mathrm{M} 21-\mathrm{OH} 1,14.3 \%$ in the case of $\mathrm{M} 21-\mathrm{OH} 3$ and $25.7 \%$ in the case of M21-OH5). The amino acids within the MAb antigen binding sites that showed strong interactions with 21-OH were also identified. These amino acids could be good candidates for mutation in order to modify binding of MAb to 21$\mathrm{OH}$ in future studies.

As shown in Fig. 4, M21-OH1 that binds to ER1 and M21-OH3 that binds to ER2 would be unlikely to have an effect on 21-OH enzyme activity as their respective binding sites are located too far away from the two active sites (i.e. the substrate binding site and the redox partner protein binding site). Our experiments showed that M21-OH1 and M21-OH3 had no effect on 21-OH enzyme activity in vitro (Fig. 1) and this is consistent with positions of ER1 and ER2 in our model relative to the location of 21-OH active sites. In contrast, MAbs that bind to ER3 (for example M21-OH5) might be expected to have an effect on 21-OH enzyme activity as ER3 is in relative proximity to the redox partner protein binding site (Fig. 4). Our experiments showed that M21$\mathrm{OH} 5$ has the ability to inhibit 21-OH enzyme activity in vitro (Fig. 1) and analysis of our model of 21-OH indicates that this may occur by M21-OH5 binding interfering with the binding of the redox partner.

As described before, patient serum 21-OH autoantibodies effectively inhibit 21-OH enzyme activity in 
vitro (12) and a recent study has shown that they inhibit the fast phase electron transfer from the NADPHp450 reductase (CPR) to 21-OH (75). The most likely mechanism of this effect is by interference in the interaction between the $\mathrm{CPR}$ and 21-OH, suggesting that the binding sites for 21-OH autoantibodies are in the proximity of the CPR binding site. The binding of 21$\mathrm{OH}$ autoantibodies in a panel of patient sera was inhibited (81\%-93\% inhibition) by a mixture of Fab or F(ab')2 preparations of our MAbs $(6,75)$. Furthermore, M21-OH5 (which had the strongest inhibiting effect on 21-OH autoantibodies binding) (6) also showed inhibition of 21-OH enzyme activity and this was probably through a similar mechanism (i.e. interference in binding of redox protein to 21-OH) (75).

The 21-OH MAb models used in our studies were built using structures of antibodies with homologous sequences available in the database. In order to verify that the MAb sequence obtained by RT-PCR was correct, we expressed recombinant M21-OH5 Fab in E. coli. Recombinant M21-OH5 Fab bound ${ }^{125}$ I-labelled 21-OH (Fig. 2) and inhibited binding of M21-OH5 IgG (derived from hybridoma cells) to 21-OH. The results of these experiments confirmed that the $\mathrm{M} 21-\mathrm{OH} 5$ sequence used for comparative modelling was that of an active 21-OH MAb.

In addition to the MAbs described in this study, we have found that a further 21-OH MAb, MAb $1 \mathrm{E} 5$ (reactive with an epitope within 21-OH aa 1-142) was able to inhibit 21-OH enzyme activity by about $80 \%$ in our in vitro experiments (data not shown). In addition, another MAb (11C6 reactive with an epitope within aa 165-280) also inhibited 21-OH enzyme activity by about $40 \%$ (data not shown). We have not carried out detailed analysis of the interactions between these MAbs and 21-OH using their respective comparative models but we looked at the positions of the epitopes for the 2 MAbs on our model of 21-OH. The aa region 1-142 extends between the entrance to channel 1 and partially overlaps the CPR binding site, and the aa region 165-280 is situated in the vicinity of and partially overlaps the entrance to channel 2. Consequently, the effects of 21-OH MAbs 1E5 and 11C6 on 21-OH enzyme activity are consistent with the location of their epitopes indicated in our model.

Overall, we have analysed the interaction between 21-OH and 21-OH MAbs using comparative models of 21-OH and the MAbs. Analysis of the locations of the $\mathrm{MAb}$ epitopes on our 21-OH model provided an explanation for the ability of M21-OH5 but not of M21$\mathrm{OH} 1$ and M21-OH3 to inhibit 21-OH enzyme activity. There was also evidence for similarities in the mechanism of inhibition of 21-OH enzyme activity by M21$\mathrm{OH} 5$ and by patient serum 21-OH autoantibodies. The results of these analyses and the models themselves provide useful tools for further studies on defining 21-OH autoantibody in more detail. Eventually, analysis of the crystal structure of $21-\mathrm{OH}$ and $21-\mathrm{OH}$ antibody complexes should be able to confirm the accuracy of our model.

\section{Acknowledgements}

Dr Chiara Dal Pra and Dr Takashi Nakamatsu were in receipt of RSR fellowships. Carol James prepared the manuscript.

\section{References}

1 Betterle C, Dal Pra C, Mantero F \& Zanchetta R. Autoimmune adrenal insufficiency and autoimmune polyendocrine syndromes: autoantibodies, autoantigens, and their applicability in diagnosis and disease prediction. Endocrine Reviews 200223 327-364.

2 Wedlock N, Asawa T, Baumann-Antczak A, Rees Smith B \& Furmaniak J. Autoimmune Addison's disease. Analysis of autoantibody binding sites on human steroid 21-hydroxylase. FEBS Letters 1993332 123-126.

3 Asawa T, Wedlock N, Baumann-Antczak A, Rees Smith B \& Furmaniak J. Naturally occurring mutations in human steroid 21-hydroxylase influence adrenal autoantibody binding. Journal of Clinical Endocrinology and Metabolism 199479 372-376.

4 Tanaka H, Asawa T, Powell M, Chen S, Rees Smith B \& Furmaniak J. Autoantibody binding to steroid 21-hydroxylase effect of five mutations. Autoimmunity 199726 253-259.

5 Nikoshkov A, Falorni A, Lajic S, Laureti S, Wedell A, Lernmark K \& Luthman H. A conformational-dependent epitope in Addison's disease and other endocrinological autoimmune diseases maps to a carboxyl-terminal function domain of human steroid 21hydroxylase. Journal of Autoimmunity 1999162 2422-2426.

6 Chen S, Sawicka J, Prentice L, Sanders JF, Tanaka H, Petersen V, Betterle C, Volpato M, Roberts S, Powell M, Rees Smith B \& Furmaniak J. Analysis of autoantibody epitopes on steroid 21hydroxylase using a panel of monoclonal antibodies. Journal of Clinical Endocrinology and Metabolism 199883 2977-2986.

7 Chomczynski P \& Sacchi N. Single-step method of RNA isolation by acid guanidinium thiocyanate-phenol-chloroform extraction. Analytical Biochemistry 1987162 156-159.

8 Kettleborough CA, Saldanha J, Ansell KH \& Bendig MM. Optimization of primers for cloning libraries of mouse immunoglobulin genes using the polymerase chain reaction. European Journal of Immunology 199323 206-211.

9 Sanders J, Jeffreys J, Depraetere H, Richards T, Evans M, Kiddie A, Brereton K, Groenen M, Oda Y, Furmaniak J \& Rees Smith B. Thyroid-stimulating monoclonal antibodies. Thyroid 200212 1043-1050.

10 Sanders J, Jeffreys J, Depraetere H, Evans M, Richards T, Kiddie A, Brereton K, Premawardhana LDKE, Chirgadze DY, Núñez Miguel R, Blundell TL, Furmaniak J \& Rees Smith B. Characteristics of a human monoclonal autoantibody to the thyrotropin receptor: sequence structure and function. Thyroid $2004 \mathbf{1 4}$ 560-570.

11 Tanaka H, Perez MS, Powell M, Sanders JF, Sawicka J, Chen S, Prentice L, Asawa T, Betterle C, Volpato M, Rees Smith B \& Furmaniak J. Steroid 21-hydroxylase autoantibodies: measurements with a new immunoprecipitation assay. Journal of Clinical Endocrinology and Metabolism 199782 1440-1446.

12 Furmaniak J, Kominami S, Asawa T, Wedlock N, Colls J \& Rees Smith B. Autoimmune Addison's disease - evidence for a role of steroid 21-hydroxylase autoantibodies in adrenal insufficiency. Journal of Clinical Endocrinology and Metabolism $1994 \quad \mathbf{7 9}$ 1517-1521.

13 Higuchi A, Kominami S \& Takemori S. Kinetic control of steroidogenesis by steroid concentration in guinea pig adrenal microsomes. Biochimica et Biophysica Acta 19911084 240-246. 
14 White PC, New MI \& Dupont B. Structure of human steroid 21hydroxylase genes. PNAS 198683 5111-5115.

15 Altschul SF, Madden TL, Schaffer AA, Zhang J, Zhang Z, Miller W \& Lipman DJ. Gapped BLAST and PSI-BLAST: a new generation of protein database search programs. Nucleic Acids Research 199725 $3389-3402$

16 Cosme J \& Johnson EF. Engineering microsomal cytochrome P450 $2 \mathrm{C} 5$ to be a soluble, monomeric enzyme. Journal of Biological Chemistry $20002752545-2553$.

17 Williams PA, Cosme J, Sridhar V, Johnson EF \& McRee DE. Mammalian microsomal cytochrome P450 monooxygenase: structural adaptations for membrane binding and functional diversity. Molecular Cell 20005 121-131.

18 Wester MR, Johnson EF, Marques-Soares C, Dansette PM, Mansuy D \& Stout CD. Structure of a substrate complex of mammalian cytochrome P450 2C5 at $2.3 \AA$ resolution: evidence for multiple substrate binding modes. Biochemistry $2003 \mathbf{4 2}$ 6370-6379.

19 Shi J, Blundell TL \& Mizuguchi K. FUGUE: sequence-structure homology recognition using environment-specific substitution tables and structure-dependent gap penalties. Journal of Molecular Biology $2001310243-257$.

20 Mizuguchi K, Deane CM \& Blundell TL. HOMSTRAD: a database of protein structure alignments for homologous families. Protein Science $199872469-2471$.

21 deBakker PIW, Bateman A, Burke DF, Miguel RN, Mizuguchi K, Shi J, Shirai H \& Blundell TL. HOMSTRAD: adding sequence information to structure-based alignments of homologous protein families. Bioinformatics 200117 748-749.

22 Deane CM, Kaas Q \& Blundell TL. SCORE: predicting the core of protein models. Bioinformatics 200117 541-550.

23 Deane CM \& Blundell TL. CODA: a combined algorithm for predicting the structurally variable regions of protein models. Protein Science $200110599-612$.

24 Miguel RN, Shi J \& Mizuguchi K. Protein fold recognition and comparative modeling using HOMSTRAD, JOY and FUGUE. In Protein Structure Prediction: Bioinformatics Approach. pp 143169. Ed. I-F Tsigelny, La Jolla, California: International University Line, 2002.

25 Laskowski RA, MacArthur MW, Moss DS \& Thornton JM. PROCHECK - a program to check the stereochemical quality of protein structures. Journal of Applied Crystallography 199326 283-291.

26 Luthy R, Bowie JU \& Eisenberg D. Assessment of protein models with 3-dimensional profiles. Nature 1992356 83-85.

27 Mizuguchi K, Deane CM, Blundell TL, Johnson MS \& Overington JP. JOY: protein sequence-structure representation and analysis. Bioinformatics $1998 \mathbf{1 4} 617-623$.

28 Gordon LM, Mobley PW, Pilpa R, Sherman MA \& Waring AJ Conformational mapping of the N-terminal peptide of HIV-1 gp41 in membrane environments using C-13-enhanced Fourier transform infrared spectroscopy. Biochimica et Biophysica Acta: Biomembranes 20021559 96-120.

29 Sutcliffe MJ, Haneef I, Carney D \& Blundell TL. Knowledge based modelling of homologous proteins, part I: three-dimensional frameworks derived from the simultaneous superposition of multiple structures. Protein Engineering 19871 377-384.

30 Sali A \& Blundell TL. Comparative protein modelling by satisfaction of spatial restraints. Journal of Molecular Biology 1993234 $779-815$.

31 deBakker PIW, DePristo MA, Burke DF \& Blundell TL. Ab initio construction of polypeptide fragments: accuracy of loop decoy discrimination by an all-atom statistical potential and the AMBER force field with Generalized Born solvation model. Proteins: Structure, Function and Genetics 200351 21-40.

32 DePristo MA, deBakker PIW, Lovell SC \& Blundell TL. Ab initio construction of polypeptide fragments: efficient generation of consistent, representative ensembles. Proteins: Structure, Function and Genetics 200351 41-55.

33 McDonald IK \& Thornton JM. Satisfying hydrogen bonding potential in proteins. Journal of Molecular Biology 1994238 777-793.
34 Hutchinson EG \& Thornton JM. HERA - a program to draw schematic diagrams of protein secondary structures. Proteins $1990 \mathbf{8}$ $203-212$.

35 Richmond TJ. Solvent accessible surface area and excluded volume in proteins. Analytical equations for overlapping spheres and implications for the hydrophobic effect. Journal of Molecular Biology $1984 \mathbf{1 7 8} 63-89$.

36 Lee B \& Richards FM. The interpretation of protein structures: estimation of static accessibility. Journal of Molecular Biology $197155379-400$.

37 Jones S \& Thornton JM. Principles of protein-protein interactions. PNAS 199693 13-20.

38 Nicholls A, Sharp K \& Honing B. Protein folding and association: insights from the interfacial and thermodynamic properties of hydrocarbons. Proteins 199111 281-296.

39 Katchalski-Katzir E, Shariv I, Eisestein M, Friesem AA, Aflalo C \& Vakser IA. Molecular surface recognition: determination of geometric fit between proteins and their ligands by correlation techniques. PNAS $1992892195-2199$.

40 Sayle RA \& Milner-White EJ. RasMol-Biomolecular graphics for all. Trends in Biochemical Sciences 199520 374-376.

41 Kabat E, Perry H, Wu T, Gottesman K. Foeller C. Sequences of Proteins of Immunological Interest, edn 5. Bethesda, MD: US Public Health Service, 1991.

42 Graham SE \& Peterson JA. How similar are P450s and what can their differences teach us? Archives of Biochemistry and Biophysics $199936924-29$.

43 Hofmann K, Bucher P, Falquet L \& Bairoch A. The PROSITE database, its status in 1999. Nucleic Acids Research 199927 215-219.

44 Miguel RN. Sequence patterns derived from the automated prediction of functional residues in structurally aligned homologous protein families. Bioinformatics $2004202380-2389$.

45 Ravichandran KG, Boddupalli SS, Hasemann CA, Peterson JA \& Deisenhofer J. Crystal structure of hemoprotein domain of P450BM-3, a prototype for microsomal P450s. Science 1993261 731-736.

$46 \mathrm{Li} \mathrm{H} \&$ Poulos TL. The structure of the cytochrome p450BM-3 haem domain complexed with the fatty acid substrate, palmitoleic acid. Nature Structural Biology 19974 140-146.

47 Podust LM, Poulos TL \& Waterman MR. Crystal structure of cytochrome P450 14a-sterol demethylase (CYP51) from Mycobacterium tuberculosis in complex with azole inhibitors. PNAS 2001 $983068-3073$.

48 Wang M, Roberts DL, Paschke R, Shea TM \& Masters BSS. Threedimensional structure of NADPH-cytochrome $\mathrm{P} 450$ reductase: prototype for FMN- and FAD-containing enzymes. PNAS 1997 $948411-8416$.

49 Charbonnier JB, Golinelli-Pimpaneau B, Gigant B, Tawfik DS, Chap R, Schindler DG, Kim SH, Green BS, Eshhar Z \& Knossow M. Structural convergence in the active site of a family of catalytic antibodies. Science 1997275 1140-1142.

50 Kristensen O, Vassylyev DG, Tanaka F, Morikawa K \& Fujii I. A structural basis for transition-state stabilization in antibody-catalyzed hydrolysis: crystal structures of an abzyme at 1.8 angstrom resolution. Journal of Molecular Biology 1998281 501-511.

51 Tanner JJ, Komissarov AA \& Deutscher SL. Crystal structure of an antigen-binding fragment bound to single-stranded DNA. Journal of Molecular Biology 2001314 807-822.

52 Keitel T, Kramer A, Wessner H, Scholz W, Schneider-Mergener J \& Hohne W. Crystallographic analysis of anti-p24 (HIV-1) monoclonal antibody cross-reactivity and polyspecificity. Cell $199791811-820$.

53 Vasudevan S, Tsuruo T \& Rose DR. Mode of binding of anti-P-glycoprotein antibody MRK-16 to its antigen. A crystallographic and molecular modeling study. Journal of Biological Chemistry 199825 (273) $413-419$.

54 Sawicki MW, Ng PC, Burkhart BM, Pletnev VZ, Higashiyama T, Osawa Y \& Ghosh D. Structure of an activity suppressing Fab fragment to cytochrome P450 aromatase: insights into the antibody-antigen interactions. Molecular Immunology $1999 \quad 36$ $423-432$ 
55 Fotinou C, Beauchamp J, Emsley P, deHaan A, Schielen WJG, Bos E \& Isaacs NW. Structure of an Fab fragment against a C-terminal peptide of hCG at $2.0 \AA$ resolution. Journal of Biological Chemistry 199822 (273) 515-518.

56 Suh SW, Bhat TN, Navia MA, Cohen GH, Rao DN, Rudikoff S \& Davies DR. The galactan-binding immunoglobulin Fab J539: an x-ray diffraction study at 2.6- $\AA$ resolution. Proteins 19861 $74-80$.

57 Rini JM, Schulze-Gahmen U \& Wilson IA. Structural evidence for induced fit as a mechanism for antibody-antigen recognition. Science $1992255959-965$.

58 Oliver CF, Modi S, Primrose WU, Lian LY \& Roberts GCK. Engineering the substrate specificity of Bacillus megaterium cytochrome P-450BM3: hydroxylation of alkyl trimethylammonium compounds. Biochemical Journal $1997327537-544$.

59 Graham-Lorence S, Amarneh B, White RE, Peterson JA \& Simpson ER. A three-dimensional model of aromatase cytochrome P450. Protein Sciences 19954 1065-1080.

60 Gotoh O. Substrate recognition sites in cytochrome P450 family 2 (CYP2) proteins inferred from comparative analysis of amino acid and coding sequences. Journal of Biological Chemistry $1992 \mathbf{2 6 7}$ 83-90.

61 Sevrioukova IF, Li H, Zhang H, Peterson JA \& Poulos TL. Structure of a cytochrome P450-redox partner electron-transfer complex. PNAS $1999961863-1868$.

62 Lin D, Zhang LH, Chiao E \& Miller WL. Modelling and mutagenesis of the active site of human P450c17. Molecular Endocrinology $19948392-402$.

63 Gonzalez FJ. The molecular biology of cytochrome P450s. Pharmacology Reviews $198940243-288$.

64 Auchus RJ \& Miller WL. Molecular modeling of human P450c17 (17alpha-hydroxylase/17,20-lyase): insights into reaction mechanisms and effects on mutations. Molecular Endocrinology 1999 13 1169-1182.

65 Lewis DFV \& Lee-Robichaud P. Molecular modelling of steroidogenic cytochromes P450 from families CYP11, CYP17, CYP19 and CYP21 based on the CYP102 crystal structure. Journal of Steroid Biochemistry and Molecular Biology 199866 217-233.
66 Mornet E \& Gibrat J-F. A 3D model of human P450c21: study of the putative effects of steroid 21-hydroxylase gene mutations. Human Genetics 2000106 330-339.

67 Williams PA, Cosme J, Ward A, Angove HC, Matak Vinkovic D \& Jhoti H. Crystal structure of human cytochrome P450 2c9 with bound warfarin. Nature $2003 \mathbf{4 2 4} 464-468$.

68 Schoch GA, Yano JK, Wester MR, Griffin KJ, Stout CD \& Johnson EF. Structure of human microsomal cytochrome P450 $2 \mathrm{c} 8$. Evidence for a peripheral fatty acid binding site. Journal of Biological Chemistry $20042799497-9503$.

69 Jukes TH \& King JL. Evolutionary nucleotide replacements in DNA. Nature $1979 \mathbf{2 8 1} 605-606$.

70 Glockshuber R, Schmidt T \& Pluckthun A. The disulfide bonds in antibody variable domains: effects on stability, folding in vitro, and functional expression in Escherichia coli. Biochemistry 199231 $1270-1279$.

71 Rudikoff S \& Pumphrey JG. Functional antibody lacking a variable-region disulfide bridge. PNAS $1986 \mathbf{8 3}$ 7875-7878.

72 Ward VK, Schneider PG, Kreissing SB, Hammock BD \& Choudary PV. Cloning, sequencing and expression of the Fab fragment of a monoclonal antibody to the herbicide atrazine. Protein Engineering 19936 981-988.

73 Padlan EA. On the nature of antibody combining sites: unusual structural features that may confer on these sites an enhanced capacity for binding ligands. Proteins 19907 112-124.

74 Fellouse FA, Wiesmann C \& Sidhu SS. Synthetic antibodies from a four-amino-acid code: a dominant role for tyrosine in antigen recognition. PNAS 2004101 12467-12472.

75 Nikfarjam L, Kominami S, Yamazaki T, Chen S, Hewer R, Dal Pra C, Nakamatsu T, Betterle C, Zanchetta R, Rees Smith B \& Furmaniak J. Mechanism of inhibition of cytochrome P450 C21 enzyme activity by autoantibodies from patients with Addison's disease. European Journal of Endocrinology 2005152 95-101.

Received 26 April 2005

Accepted 9 September 2005 